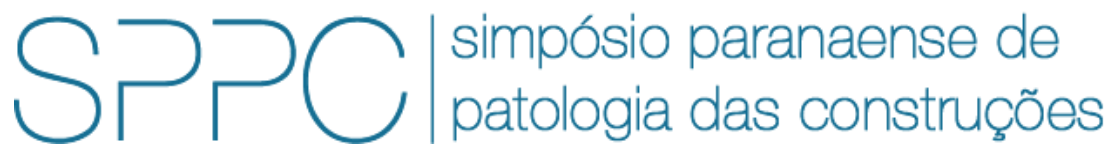

ISSN 2526-7248 artigo 2SPPC2007, pp. 537-546, 2017

\title{
Manifestações Patológicas decorrentes em Solo Grampeado e Cortina Atirantada
}

\author{
Ana Paula Mikos ${ }^{1}$, Manuela Cabral Caetano², Larissa Roedel ${ }^{3}$, Vitor Pereira Faro ${ }^{4}$ \\ 1 Doutoranda, Universidade Federal do Paraná, anamikos@ufpr.br \\ 2 Estudante, Universidade Federal do Paraná, manuela.c.caetano@gmail.com \\ 3 Estudante, Universidade Federal do Paraná, larissa.roedel.8@gmail.com \\ 4 Professor Doutor, Universidade Federal do Paraná, vpfaro@ufpr.br
}

Resumo: Estruturas de contenção têm como finalidade conter maciços de solos e rochas, de forma a impedir escorregamentos e fornecer estabilidade. As soluções com solo grampeado e cortina atirantada apresentam barras de aço inseridas no terreno envoltas com calda de cimento. $O$ artigo propõe apresentar e discutir os principais agentes deflagradores de manifestações patológicas nas contenções, bem como as principais maneiras de identificar, evitar e minimizar danos que podem ocorrer devido a falhas. As principais manifestações patológicas encontradas nesses tipos de estruturas são decorrentes da má execução e interação do aço e concreto com os agentes externos, principalmente a corrosão das barras de aço. Um acompanhamento adequado na fase construtiva, com utilização de proteção anticorrosiva nas barras e manutenções periódicas nas contenções e no sistema de drenagem podem evitar obras de intervenção e garantir um bom desempenho da estrutura.

Palavras-chave: Manifestações Patológicas. Solo Grampeado. Cortina Atirantada. Corrosão.

Abstract: The retaining structures purpose is stabilize slopes with soils and rocks, in order to prevent landslides and provide stability. The solutions with soil nailing and anchored wall have steel bars inserted in the ground involved with grouting. This article proposes to present and discuss the main agents that cause pathological manifestations in retaining structures, as well as the main ways to identify, avoid and minimize damage that can occur due to failures. The main pathological manifestations found in these types of structures are due to the bad execution and interaction of steel and concrete with the external agents, mainly the corrosion of steel bars. Adequate construction supervision and periodic conservation on structures can avoid intervention works and ensure a good performance of the structure.

Keywords: Pathological manifestations. Retaining structures. Soil nailing. Anchored wall. Corrosion. 
MIKOS, A. P.; ET AL., MANIFESTAÇÕES PATOLÓGICAS DECORRENTES EM SOLO GRAMPEADO E CORTINA ATIRANTADA. $2^{\circ}$ Simpósio Paranaense de Patologia das Construções (2 SPPC), artigo 2SPPC2007, pp. 537-546, 2017. DOI:

\section{Introdução}

Estruturas de contenção com chumbadores no maciço são amplamente utilizadas em cortes com geometria instável ou para implantação de subsolos, taludes existentes sem estabilidade satisfatória, ou taludes rompidos. O objetivo principal é a melhoria do solo com a estabilização geral do maciço, e para isso deve ser considerado um paramento na face em conjunto com sistema de drenagem.

Embora os acidentes ocorridos em solo grampeado e cortina atirantada não sejam muito divulgados, eles ocorrem normalmente pela soma de diversos fatores, entre eles: falhas executivas, ineficiência ou ausência de sistema de drenagem, e processos de corrosão. Como os elementos são enterrados no solo, estão sujeitos continuamente a fatores que podem degradar sua integridade estrutural. Desse modo, a estabilidade e a capacidade de atingir os esforços para que foram projetados é dependente do seu estado de conservação. Em solo grampeado, a principal falha apresentada na literatura é o preenchimento incompleto da calda de cimento ao longo do furo, que pode causar instabilidade e deixar os grampos suscetíveis à corrosão [1]

Nas cortinas atirantadas, a manifestação patológica mais relevante é a corrosão, presente próximo a cabeça do tirante e no trecho livre, onde há maior presença de oxigênio e água. As principais cortinas atirantadas do Brasil foram executadas na década de 1970, e atualmente apresentam mais de 40 anos, o que indica procedimentos não normatizados e muitas vezes sem controle de qualidade [2]. Logo, se faz importante a realização de inspeções e manutenções periódicas ao longo da vida útil e um acompanhamento da etapa construtiva de obras novas, a fim de garantir a segurança das contenções e sua funcionalidade.

\section{Revisão Bibliográfica}

Em soluções tradicionais de estabilização de maciços de solo e rocha são utilizados os muros de arrimo, que se opõem aos empuxos verticais com peso próprio, ou por flexão, com necessidade de armadura. Os muros podem ser construídos de diversos materiais, como: alvenaria, concreto, pedras, sacos de solo-cimento, gabiões, pneus, entre outros. No entanto, essas soluções podem se tornar inviáveis principalmente para grandes desníveis e devido ao grande volume de escavações. Desse modo, podem ser utilizadas barras de aço no solo envoltas por calda de cimento, como o solo grampeado, de modo passivo, e a cortina atirantada, com elementos ativos, ou seja, sem movimentações indesejáveis.

\subsection{Solo Grampeado e Cortina Atirantada}

Cortinas atirantadas são estruturas antigas, utilizadas no país desde 1957, com grande influência do engenheiro Antônio da Costa Nunes, que desenvolveu a tecnologia de chumbamento e ancoragem no solo, no Estado do Rio de Janeiro. Entretanto, a disseminação da técnica ocorreu no início da década de 1970, muitas vezes substituindo os tradicionais muros de arrimos de gravidade e flexão [3]. Os elementos instalados podem ser monobarra, cordoalhas ou fios, e tem o objetivo de aumentar a resistência ao cisalhamento do solo com o aumento da tensão normal atuante ao longo da linha de ruptura. 
O tirante pode ser dividido em três partes principais: cabeça, trecho ancorado e trecho livre. A cabeça do tirante está localizada na parte externa da cortina, constituída de placa de apoio, cunha de grau e bloco de ancoragem, sem contato com o solo, e transfere a carga do tirante para a estrutura de paramento. $O$ trecho ancorado é encarregado de transmitir os esforços de tração do tirante para o solo, envolvendo-o com material aglutinante composto de calda de cimento ou argamassa. Entre esse trecho e a cabeça está situado o trecho livre, sem contato com a calda de injeção [4]. O comprimento dos elementos deve ser suficiente para que o trecho ancorado, que forma o bulbo esteja além da superfície de deslizamento.

Com base na larga experiência adquirida com a construção de cortinas atirantadas, os engenheiros brasileiros começaram a utilizar e adaptar-se ao solo grampeado, devido a sequência executiva semelhante. O solo grampeado foi desenvolvido na década de 1960 para aplicação em túneis convencionais (NATM) e, no Brasil foi utilizado pela primeira vez em 1970 durante a construção do sistema de abastecimento de água Cantareira em São Paulo [3]. Desde então, tal metodologia se tornou comumente utilizada em cortes para implantação de subsolos e na contenção de taludes naturais com estabilidade insatisfatória ou rompidos.

O solo grampeado é composto por dois elementos principais: os chumbadores e o preenchimento. Os chumbadores são elementos semirrígidos que promovem a estabilização do maciço devido à resistência à tração, e são mobilizados em resposta ao movimento lateral e a deformação do solo. O grampo é inserido em uma perfuração e posteriormente é realizado o preenchimento, normalmente com cimento e água. A calda de cimento tem a função de transferir as tensões de cisalhamento da deformação do solo e das barras metálicas e as tensões de tração para o solo envolvente, além de proporcionar certo nível de proteção contra corrosão [5]. O grampo é ligado ao paramento por meio de uma placa de apoio e rosca, e a face, que não tem função estrutural, é realizada apenas com concreto projetado, telas metálicas flexíveis ou executados em talude natural com hidro-semeadura.

Estruturas de estabilização com solo grampeado requerem equipamentos menores comparados à cortina atirantada. Sua aplicação, em geral, apresenta maior custobenefício, a estrutura suporta pequenas deformações e a instalação é relativamente rápida. Por outro lado, Lazarte [5] afirma que a estrutura geralmente não pode ser vertical, pois o projeto se torna mais difícil e dispendioso e alguns tipos de solo podem tornar a estrutura inviável, como solos expansivos, orgânicos, não coesivos e mal graduados, com grande quantidade de pedras e pedregulhos ou granulares com alto nível do lençol freático. Além disso, cortinas atirantadas apresentam custos mais elevados e a execução demanda tempo, mão-de-obra e equipamentos especializados [6], porém acabam se tornando viáveis se necessitar de grampos muito compridos na estabilização com solo grampeado, e quando não pode haver nenhuma deformação do maciço.

\subsubsection{Sistema de Drenagem}

O sistema de drenagem deve ser considerado nas obras de contenção, pois quando ausentes ou mal executados, a percolação de água pelo maciço gera a elevação do nível do lençol freático e saturação das camadas superficiais. Tal fato causa 0 aumento da poropressão e do empuxo total, reduzindo a tensão efetiva, com consequente redução da resistência ao cisalhamento do solo. Pressões neutras ao 
longo de potenciais superfícies de ruptura podem se desenvolver, reduzindo a estabilidade. Também pode ocorrer a redução da coesão aparente, pela sucção através da saturação dos solos não-saturados, e ação erosiva interna (piping) [7]. O aumento da carga suportada pela contenção devido a presença de água, na maioria das vezes não é considerada em projeto e as falhas no sistema de drenagem ainda podem afetar a qualidade e durabilidade do concreto e das barras de aço.

Um sistema de drenagem eficiente deve ser previsto em obras de contenção, uma vez que o custo é muito baixo comparado com aumento da segurança. Durante a execução da obra, deve ser definida a profundidade do nível do lençol freático a fim de verificar o dimensionamento dos drenos no projeto. De tal modo, os dispositivos devem ser instalados antes da construção da parede de concreto, para evitar o fluxo de água dentro do maciço. Devem ser consideradas a drenagem profunda, de paramento e superficial, como apresentado na Figura 1.

Solo grampeado

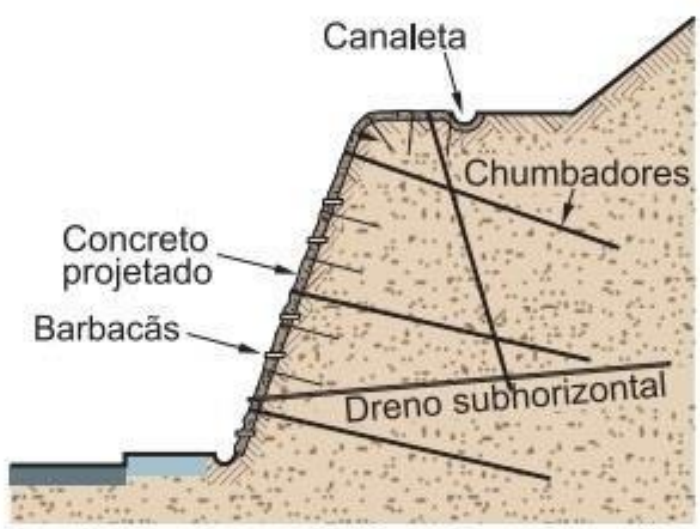

Cortina atirantada

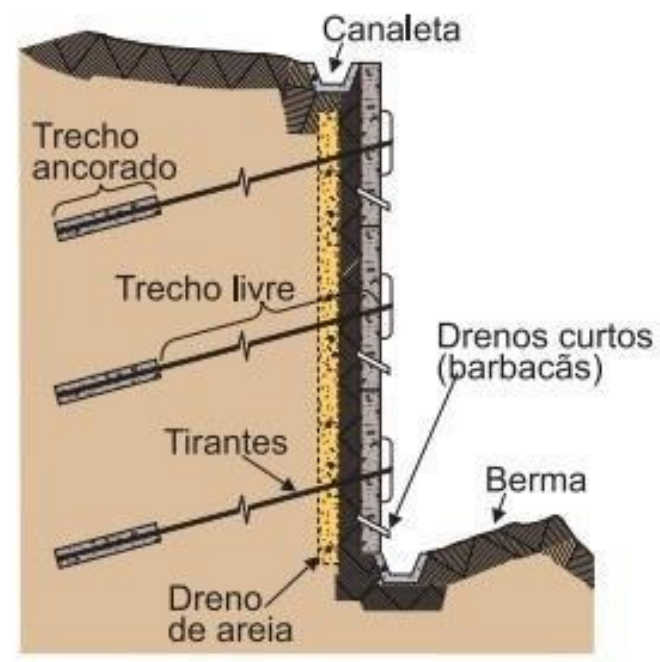

Figura 1: Sistemas de drenagem em solo grampeado e cortina atirantada [8]

A drenagem profunda consiste na captação de água distante do paramento, para evitar o afloramento pela face, com o uso de drenos sub-horizontais profundos (DHP). A drenagem de paramento deve proporcionar a organização do fluxo de água que converge ao paramento pelo maciço. Normalmente são utilizados drenos curtos do tipo barbacã, drenos de areia ou geossintéticos na face interna da face. A drenagem superficial coleta e direciona o fluxo da crista e do pé do talude, bem como a água coletada pelos drenos de paramento e profundos, com o uso de canaletas e escadas hidráulicas, a fim de encaminhar para um ponto de captação ou descarga [9].

Procedimentos simples como inspeções visuais e manutenção dos drenos podem evitar o desenvolvimento de manifestações patológicas nas estruturas [10]. Alguns aspectos do paramento podem indicar a presença de água e umidade no maciço, tais como: manchas superficiais, eflorescências, musgos e líquens, vegetação e a própria surgência de água pela estrutura ou juntas. O surgimento de manifestações patológicas em estruturas de contenções normalmente está diretamente ligado ao sistema de drenagem. 


\subsection{Falhas nas Contenções}

Os principais problemas em estruturas de solo grampeado ocorrem devido ao preenchimento incompleto do furo com a calda de cimento, que é uma condição essencial para garantia do desempenho da contenção. As principais falhas encontradas são: vazios no final da barra, redução da seção transversal do preenchimento e defeitos próximos à cabeça da barra. As falhas no preenchimento ocorrem pela falta de centralizadores, ausência de tubo guia, consistência da nata muito rígida ou muito fluída ou execução de perfurações maiores que o comprimento das barras. Manifestações patológicas também são normalmente relacionadas à problemas construtivos na instalação e falha de controle na execução. Essas anomalias podem causar maiores deformações da contenção, reduzir a capacidade de carga do chumbador e deixar a barra exposta e suscetível à corrosão. [1].

Souza et al. [11] executaram grampos com diferentes fases de injeção da calda de cimento em um campo experimental, e constataram que quando a injeção é realizada somente com bainha, ou seja, somente uma injeção, a exsudação da calda de cimento provoca vazios ao longo do furo com um preenchimento incompleto, como apresenta a Figura 2. Para evitar essas falhas, deve ser executada pelo menos mais uma fase de reinjeção no furo, o que muitas vezes não foi realizado em obras antigas.

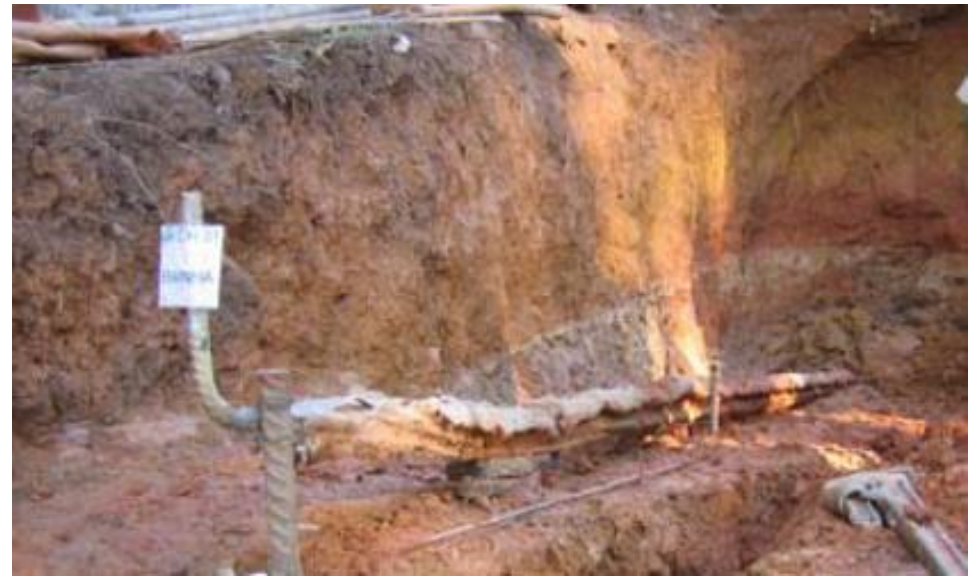

Figura 2: Falhas ao longo do furo [11]

De modo geral, a utilização de procedimentos que atendam aos padrões de qualidade atuais não se aplica à maior parte das instalações antigas e que, muitas vezes, os grampos eram instalados sem nenhuma proteção anticorrosiva. Como nesse tipo de estrutura a injeção da calda de cimento ocorre por todo o furo, o risco de corrosão está diretamente ligado à existência de uma eventual falha na injeção, onde os vazios de concretagem mantêm a barra exposta e suscetível à processos corrosivos. A proteção anticorrosiva é um aspecto importante no solo grampeado, de modo que o desempenho e a vida-útil destas contenções dependem também de a capacidade do grampo resistir à corrosão [12].

Segundo Ortigão et al. [3] e Pitta et al. [2], a experiência nacional com cortinas atirantadas indica que a corrosão é o grande responsável por falhas na zona livre e próximo à cabeça do tirante, onde há maior presença de oxigênio, e forma um composto pouco resistente e muito expansivo. Isto ocorre principalmente quando a proteção anticorrosiva é inadequada e existe presença de água no maciço. Em 
inspeções realizadas na cidade do Rio de Janeiro em obras com mais de 30 anos, indicou que grande parte dos tirantes se apresentavam soltos ou rompidos devido à processos avançados de corrosão e sem proteção na cabeça das barras. A primeira norma brasileira é de 1975, contudo, mesmo em vigor, algumas obras seguiam os procedimentos internos da empresa, não tomando os devidos cuidados na execução das contenções [2].

As cortinas atirantadas são as estruturas de contenção com maior chance de colapso por corrosão, e as consequências são preocupantes, uma vez que a falha de um elemento pode causar sobrecarga nos tirantes adjacentes, podendo resultar no colapso da estrutura [13]. Em cortinas atirantadas, que são executadas com aço protendido, existem fatores mais agravantes, como a corrosão sob tensão, e também em relação a menor área de seção das cordoalhas ou fios, de modo a tornar a corrosão mais acentuada. Como não existe acesso às partes enterradas da contenção, é de extrema importância atentar-se aos indícios externos de manifestações patológicas, como manchas de umidade e ferrugem, corrosão na cabeça do tirante e capacete de concreto trincado. Na Figura 3 pode-se observar a cabeça de um tirante com presença de corrosão, sem capacete, que provavelmente caiu devido ao produto expansivo gerado pela corrosão das barras de aço.

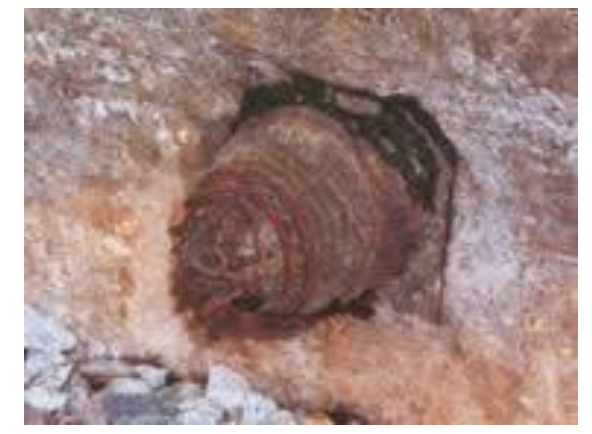

Figura 3: Corrosão da cabeça do tirante [11]

\subsubsection{Proteção Anticorrosiva das Barras}

A corrosão é a deterioração das propriedades de um metal pela reação química ou eletroquímica com o meio que o envolve [14]. A corrosão eletroquímica é a mais comum e seus processos demandam a presença de água, que atua como solução condutora de eletricidade, e uma diferença de potencial (ddp). No caso das contenções estudadas, a água presente nos poros do solo é a solução condutora (eletrólito) que atua como meio de transporte de agentes químicos agressivos, tais como sulfatos e cloretos e, com isso, pode-se iniciar o processo de corrosão nas barras de aço [12].

O principal objetivo de proteger o tirante contra a corrosão é garantir que, durante a vida útil para a qual esse tirante foi projetado, não haja comprometimento da segurança da obra. A proteção anticorrosiva deve ser aplicada tanto em grampos como em tirantes, de acordo com as recomendações da norma NBR 5629 - Execução de Tirantes Ancorados no Terreno [4], considerando o grampo como o trecho ancorado de um tirante [9]. A Associação Brasileira de Normas Técnicas (ABNT) normatiza a aplicação de dupla proteção anticorrosivas em tirantes permanentes, com vida útil de mais de 2 anos, para qualquer tipo de agressividade do solo, como: tintas 
e resinas, Epóxi, fluidos a base de betume, tubo de polietileno, graxa, nata ou argamassa à base de cimento e/ou tratamento superficial de galvanização ou zincagem. Também devem ser utilizados centralizadores de 1,5 $\mathrm{m}$ a 2,0 $\mathrm{m}$, a fim de garantir um recobrimento mínimo das barras. Para definição do tipo de proteção anticorrosiva deve-se identificar a agressividade do meio, o nível do lençol freático, bem como as consequências de um possível colapso da estrutura [4].

\subsubsection{Potencial Corrosivo do Solo}

Para o dimensionamento e elaboração de projetos de contenções, é necessário identificar e conhecer as características geológicas e geotécnicas das camadas do subsolo que serão submetidas aos estudos de estabilidade. Desse modo, com ensaios químicos e físicos do solo pode-se prever seu potencial corrosivo. Nos estudos de corrosão, a análise química dos solos está limitada à determinação dos componentes que são solúveis em água, definidos pela natureza, quantidade de sais e teor de umidade do solo. Por outro lado, as características físicas dos solos que têm influência no processo de corrosão são as que determinam a permeabilidade, como a granulometria e mineralogia [14].

A resistividade elétrica é uma característica única do solo e pode ser determinada em campo, por meio de métodos geofísicos, e em laboratório. Esse parâmetro indica a capacidade do solo em resistir a passagem de uma corrente elétrica. Quanto menor a resistividade, maior a condutividade elétrica, ou seja, a passagem de corrente elétrica, e nesse caso maior a facilidade de ocorrer corrosão. Segundo Boszczowski [15], a resistividade de um solo está diretamente relacionada à quantidade de compostos iônicos solúveis, quanto maior essa quantidade, menor a resistividade. A água dissolve esses compostos, portanto, se não houver água, não há dissolução de compostos iônicos e não há passagem de corrente. No entanto, outros parâmetros também influenciam a resistividade elétrica, como a umidade e a saturação, a granulometria, o índice de vazios e a porosidade, além da estrutura do solo.

A resistividade elétrica do solo diminui com o aumento do grau de saturação, ou seja, com o aumento da umidade, pois favorece a passagem de corrente elétrica pela água. No entanto, quanto maior o índice de vazios, maior a resistividade das amostras. Em relação a granulometria, o aumento de finos no solo, reduz a porosidade e o índice de vazios, pois os grãos menores ocupam os vazios formados entre os grãos maiores de areia, diminuindo a resistividade, e aumentando a condutividade. Solos finos são potencialmente mais corrosivos que solos granulares, pois apresentam uma menor circulação de ar nos poros e maior capacidade de retenção de água, resultando em baixa permeabilidade e menor capacidade de drenagem [12]. Ensaios com amostras indeformadas apresentaram valores superiores de resistividade comparado com amostras deformadas com as mesmas características de campo (umidade e índice de vazios), indicando a existência de cimentação na estrutura do solo o que não é possível reproduzir com amostras deformadas [15].

\section{Discussão}

O colapso de uma estrutura de contenção pode gerar inúmeros danos econômicos, sociais e ambientais, e no pior caso, resultar na perda de vidas humanas. Geralmente 
uma estrutura indica que não está em perfeitas condições antes de falhar. Os procedimentos adotados para desenvolver medidas preventivas, corretivas, e avaliar sinistros ocorridos em contenções, são divididos em 3 etapas principais: inspeções in loco, apoio logístico e de campo, e análise dos dados e diagnóstico. Inicialmente deve ser realizada visitas de campo, a fim de obter informações quantitativas e qualitativas. As informações quantitativas podem ser obtidas com inspeções visuais, como altura, comprimento, espessura da contenção, área danificada e distância das edificações ameaçadas. Também são realizadas avaliações qualitativas, não sendo necessário grande precisão, para obter informação sobre a gravidade das falhas e manifestações patológicas identificadas. São avaliadas a idade aparente da estrutura, presença de drenagem, tipologia construtiva, fissuras, deformações, análise da vizinhança e área ao entorno. Dentre 173 estruturas de contenções avaliadas em Joinville - SC, o autor acredita que apenas $27 \%$ devem ter sido projetadas e executadas por profissionais qualificados. Ainda foi detectado que $47 \%$ do total não possuía nenhuma espécie de sistema de drenagem e apenas $15 \%$ apresentavam drenagem superficial e profunda [16]. Para auxiliar na avaliação de estruturas de contenção, pode-se utilizar um simples Check-list de modo a identificar a obra e realizar acompanhamento de condição ao longo do tempo [10,16].

Todas as medidas devem ser tomadas para evitar falhas em estruturas de contenção e evitar acidentes. Na Figura 4 é apresentado um acidente que ocorreu em um trecho da rodovia ERS-115, com a ruptura de uma cortina atirantada, com presença de rachaduras e afundamento no pavimento. O acidente acarretou na interdição da estrada por aproximadamente um mês para recuperação, o que gerou elevados danos sociais, ambientais e econômicos, com isolamento de comunidades [17].

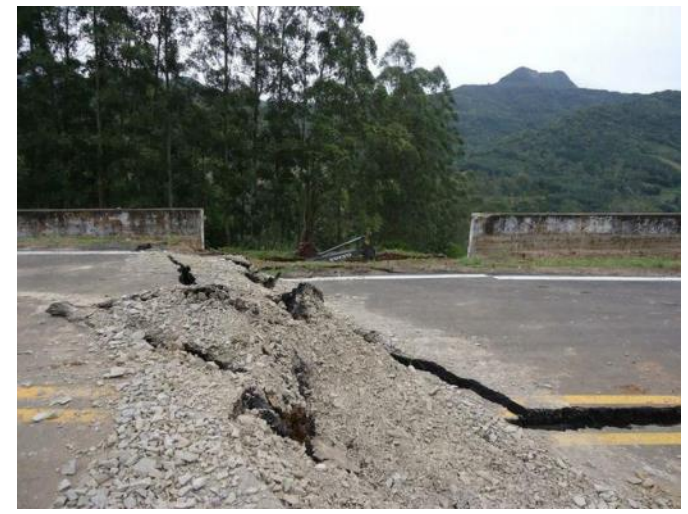

Figura 4: Ruptura de cortina atirantada na ERS-115 [17]

Como grande parte das manifestações patológicas decorrentes nessas contenções são devido a presença de água no maciço, deve-se prever um adequado sistema de drenagem superficial, profunda e de paramento nas obras, e realizar desobstrução das drenagens existentes.

Falhas no preenchimento da calda de cimento é uma anomalia comum em solo grampeado, que é muitas ocorre pela má execução da obra, e que também pode gerar corrosão das barras. A corrosão é uma das principais manifestações patológicas nas cortinas atirantadas, para isso deve ser previsto uma adequada proteção anticorrosiva, que pode ser definido de acordo com a vida útil do elemento e do nível de agressividade do terreno [4]. 


\section{Conclusões}

As estruturas com solo grampeado e cortina atirantada apresentam elementos enterrados no solo e estão continuamente sujeitos a fatores que degradam sua integridade estrutural. Desse modo, é importante garantir uma boa execução em obras novas, com proteção anticorrosiva eficiente nos grampos e tirantes de acordo com o potencial corrosivo do solo. Também deve-se realizar acompanhamento periódico e manutenções eventuais ao longo da vida útil das contenções. Falhas podem gerar perdas de vidas humanas, comprometer a segurança de pessoas e veículos em circulação próximo a estrutura, afetar construções adjacentes, e pode gerar elevados custos sociais e econômicos.

Deve-se atentar as características do paramento, que podem indicar a presença de água e umidade no maciço, tais como: manchas superficiais, eflorescências, musgos, líquens, vegetação e a própria surgência de água pela estrutura ou juntas. A presença de água no maciço além de gerar uma carga extra na contenção, também facilita o desenvolvimento de processos corrosivos nas barras de aço, principalmente próximo ao paramento. Essa manifestação pode ser identificada com manchas avermelhadas de ferrugem, corrosão na cabeça do tirante e capacete de concreto trincado. Procedimentos simples como inspeções visuais e manutenção da estrutura de contenção e do sistema de drenagem devem ser frequentes, de modo a evitar obras de intervenção e garantir a estabilidade e segurança da contenção.

\section{Referências}

[1] Jayawickrama, P. W.; Tinkey, Y.; Gong, J.; Turner, J. Non-Destructive Evaluation of Installed Soil Nails. Report No. FHWA/TX 07-258 p. Texas: 2007.

[2] Pitta, C. A., Souza, G. J. T., Zirlis, A. C., Ferreira, J. F. C. Quanto tempo durarão as cortinas atirantadas executadas a partir da década de 70 ? 30 anos? XIII COBRAMSEG - Congresso Brasileiro de Mecânica dos Solos e Engenharia Geotécnica. 2006.

[3] Ortigão, J. A. R., Palmeira, E. M., Zirlis, A. Experience with soil mailing in Brazil: 1970-1994. Proceedings of the Institution of Civil Engineers, Geotechnical Engineering. Londres:1995.

[4] Associação Brasileira de Normas Técnicas. NBR 5629: Execução de tirantes ancorados no terreno. Rio de Janeiro, 2006.

[5] Lazarte, C. A., Robinson, H., Gómez, J. E., Baxter, A., Cadden, A., Berg, R. Soil Nail Walls Reference Manual. National Highway Institute. (No. FHWA-NHI-14007). Washington: 2015.

[6] Massad, F. Obras de terra: curso básico de geotecnia. Editora Ofinina de Textos, $2^{a}$ edição. São Paulo: 2010.

[7] Bastos, I.G., Wolle, C.M. E Futai, M.M. Estabilização de Encostas Através de Drenagem Profunda. XVII COBRAMSEG - Congresso Brasileiro de Mecânica dos Solos e Engenharia Geotécnica. Goiânia: 2014. 
[8] Gerolla, G. Terra Firme. Técnne, São Paulo. Edição 123. Junho de 2007. Editora PINI. Disponível em: < http://techne.pini.com.br/engenharia-civil/123/ artigo285379 -6.aspx>. Acesso em: 15 mar 2016.

[9] Solotrat. Manual de Serviços Geotécnicos Solotrat. 5ª ed. 108 p. São Paulo: 2015.

[10] Caetano, C. C., Roedel, L., Mikos, A. P., Faro, V. P., Sestrem, L. P. Drenagem em Obras de Contenções Viárias. XVIII COBRAMSEG - Congresso Brasileiro de Mecânica dos Solos e Engenharia Geotécnica. Belo Horizonte: 2016.

[11] Souza, G. J. T.; Pitta, C. A.; Zirlis, A. C. Solo grampeado - aspectos executivos do chumbador. IV COBRAE - Conferência Brasileira sobre estabilidade de encostas. Salvador: 2005

[12] Shiu, Y. K.; Cheung, W. M. Long-term durability of steel soil nails. Geo Report 135. Geotechnical engineering office. Civil engineering and development department. Hong Kong: 2003.

[13] Irvin, C. Mothersille, D.K.V. Corrosion protection options for permanent ground anchorages, Proceeding of the International Conference on Ground Anchorages and Anchored Structures in Service, Londres, Reino Unido. 2007.

[14] Serra, E.T. Corrosão e Proteção Anticorrosiva dos Metais no Solo. 1a ed. 180 p. Rio de Janeiro: 2015.

[15] Boszczowski, R. B. Avaliação de propriedades mecânicas e hidráulicas de um perfil de alteração de granito-gnaisse de Curitiba, PR. Tese de Doutorado. Pontifícia Universidade Católica do Rio de Janeiro. Rio de Janeiro: 2008.

[16] Luiz, G. Diagnóstico de Estabilidade Aparente de Encostas - Hierarquização de Riscos e Planejamento de Intervenções. $5^{\circ}$ Congresso Internacional sobre Patologia e Reabilitação de Estruturas. Curitiba: 2009.

[17] MPRS. MP ajuíza ação para evitar deslizamentos no Polo Rodoviário de Gramado. Ministério Público do Rio Grande do Sul, 28 de maio de 2013. Disponível em: < http://www.mprs.mp.br/civel/noticias/id32034.html>. Acesso em: 24/03/2017. 